\title{
UBUniversidad de Boyacá
}

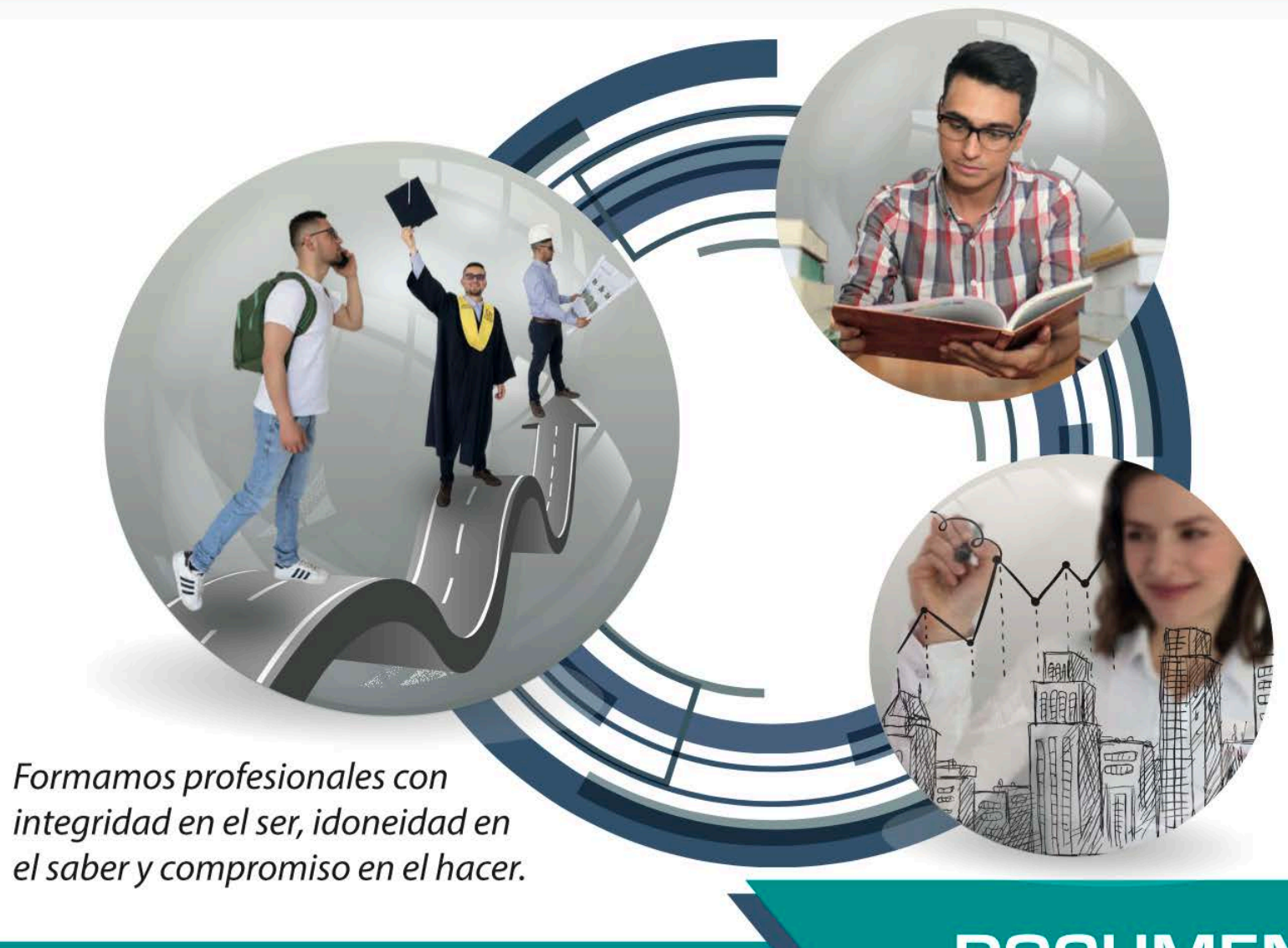

\section{DOCUMENTOS INSTITUCIONALES}

Rectoría Serie 2 № 16

\section{POLITICA EDITORIAL}

Acuerdo No. 093 de diciembre 10 de 2018 - Consejo de Fundadores 


\section{UB Universidad de Boyacá}

$\overline{\text { Vigilada Mineducación }}$

\section{POLÍTICA EDITORIAL}





\section{UB Universidad de Boyacá}

$\underline{\text { Vigilada Mineducación }}$

Personería Jurídica 6553 del 25 de mayo de 1981

RESOLUCIÓN No. 2910/2004 MINISTERIO DE EDUCACIÓN NACIONAL

\section{ÓRGANOS DE DIRECCIÓN}

\section{CONSEJO DE FUNDADORES}

\section{Presidente}

Dr. Osmar Correal Cabral

\section{Vicepresidente}

Ec. Mg. Camilo Correal C.

Ing. Mg. Rodrigo Correal Cuervo

Ing. Mg. Andrés Correal C.

\section{Rectora}

Dra. Rosita Cuervo Payeras 


\title{
CONSEJO DIRECTIVO
}

\author{
Presidente \\ Dr. Osmar Correal Cabral
}

\section{Rectora}

Dra. Rosita Cuervo Payeras

\section{Vicepresidente}

Ec. Mg. Camilo Correal Cuervo

Representante de la comunidad Abg. Mg. Manuel José Bernal García

\section{Representante de los docentes}

Abg. Mg. Ruby Elsa Amador Díaz

Representante de los egresados

Abg. Mg. Mónica Alexandra Álvarez Mejía

\section{Representante de los estudiantes}

Leidy Yohana Rojas Torres 


\section{DIRECTIVOS}

\section{RECTORÍA}

Rectora: Doctora Rosita Cuervo Payeras

Asistente Rectoría: Abg. Mg. Mónica Alexandra Álvarez

Secretaria General: Adm. Mg. Alba Judith Quiroga

Asesora Jurídica: Abg. Mg. Yeimy Rodríguez

Directora División Financiera: Cont. Púb. Mg. María Antonieta Ferro

Directora División de Bienestar Universitario: Psi. Mg. Mónica Patricia Pérez

Jefe Oficina de Planeación: Ec. Mg. William Alberto Sanabria

\section{DIRECTIVOS ACADÉMICOS}

\section{VICERRECTORÍA ACADÉMICA}

Vicerrector Académico: Ing. Mg. Rodrigo Correal

Subdirectora Académica de Sede: Psic. Mg. Paola Burgos

Director División de Calidad Académica: Lic. Mg. Germán Arias

Directora División de Acreditación: Fisiot. Mg. Amanda Elizabeth García

Director División de Postgrados: Lic. Mg. Rodolfo Alfonso Gamboa

Directora División de Capacitación y Formación Docente: Bact. Mg. Claudia Patricia Jaimes

Decano Facultad de Ciencias e Ingeniería: Ing. Mg. Carlos Rafael Lara

Decana Facultad de Ciencias Jurídicas y Sociales: Com. Soc. Mg. Ethna Yanira Romero

Decano Facultad de Ciencias Administrativas y Contables: Adm. Mg. Víctor Julio Pardo

Decana Facultad de Arquitectura, Diseño y Urbanismo: Arq. Mg. María Leonor Mesa

Decana Facultad de Ciencias Humanas y Educativas Psic. Mg. Claudia Inés Bohórquez

Decana Facultad de Ciencias de la Salud: Méd. Mg. Gloria Eugenia Camargo

\section{VICERRECTORÍA DE EDUCACIÓN VIRTUAL}

Vicerrectora de Educación Virtual: Ing. Mg. Carmenza Montañez T.

Directora División de Gestión Académica: Ing. Mg. Erika María Sandoval 


\section{VICERRECTORÍA DE INVESTIGACIÓN, CIENCIA Y TECNOLOGÍA}

Vicerrectora de Investigación, Ciencia y Tecnología: Ing. Mg. Patricia Quevedo Directora de CIPADE: Fisiot. Mg. Elisa Andrea Cobo

Director División de Publicaciones: Ing. D.G. Mg. Camilo Agudelo

Directora División de Informática, Tecnología y Telecomunicaciones:

Ing. Mg. Martha Isabel Suárez

Jefe Politeca: Adm. Mg. María Elia Monguí

\section{DIRECTIVOS ADMINISTRATIVOS}

\section{VICERRECTORÍA DE DESARROLLO INSTITUCIONAL}

Vicerrector de Desarrollo Institucional: Ing. Mg. Andrés Correal

Directora División de Responsabilidad Social: Lic. Mg. Imelda Consuelo Botero Directora División de Proyectos Especiales: Ing. Mg. Gloria Elizabeth Grimaldo Directora División de Relaciones Internacionales e Interinstitucionales:

Adm. Mg. María Fernanda Perilla

Directora División de Egresados: Adm. Ángela Carolina Bernal

Jefe Oficina de Comunicaciones y Mercadeo: Com. Soc. Mg. Juan Pablo Medina Directora Sede Sogamoso: Quím. Mg. Alba Lorena Benavides

Directora Sede Yopal: Adm. Neg. Int. Laura Oliveros

\section{VICERRECTORÍA ADMINISTRATIVA Y DE INFRAESTRUCTURA}

Vicerrector Administrativo y de Infraestructura: Ec. Mg. Camilo Correal

Directora División de Recursos Humanos: Adm. Luz Mery Ortiz

Directora División Administrativa: Adm. Luz Marina Borda

Director División de Infraestructura: Ing. Leonardo Gutiérrez 


\section{DISEÑO Y DIAGRAMACIÓN}

División de Publicaciones

\section{Diseño de carátula}

D.G. Esp. Diana Lizeth Becerra Castro

\section{Diagramación}

Ing. D.G. Mg. Johan Camilo Agudelo Solano

\section{Impresión}

Búhos Editores Ltda.

(c) Ediciones Universidad de Boyacá

Carrera 2a. Este $\mathrm{N}^{\circ}$ 64-169

Tels.: (8) 7452742 - 7450000 Ext. 3104 www.uniboyaca.edu.co

publicaciones@uniboyaca.edu.coTunja-Boyacá-Colombia

Esta edición y sus características gráficas son propiedad de la

\section{UB Universidad de Boyacá}

\section{(C) 2019}

Queda prohibida la reproducción parcial o total de este libro, por medio de cualquier proceso reprográfico o fónico, especialmente fotocopia, microfilme, offset o mimeógrafo (Ley 23 de 1982) 


\section{Contenido}

PRESENTACIÓN.

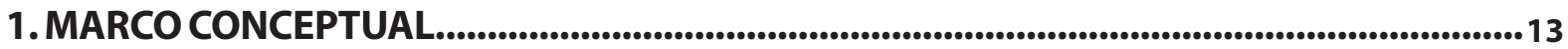

1.1 PROPIEDAD INTELECTUAL...........................................................................................................................................13

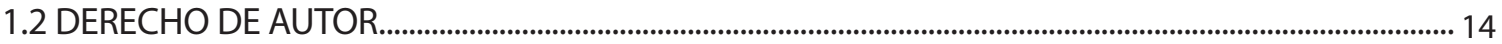

1.3 DERECHOS INHERENTES AL DERECHO DE AUTOR.................................................................................... 16

1.4 DERECHOS MORALES................................................................................................................................. 16

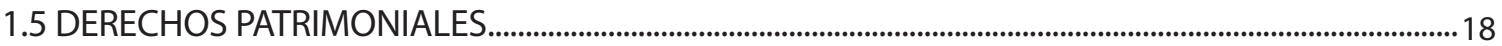

1.6 OBJETO DE PROTECCIÓN DE DERECHO DE AUTOR...................................................................................... 20

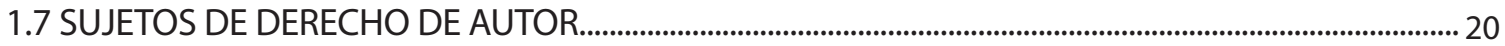

1.8 CLASES DE OBRAS SEGÚN LA LEY DE DERECHO DE AUTOR.............................................................. 21

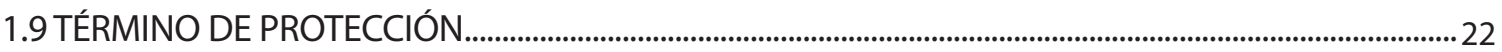

1.10 LIMITACIONES Y EXCEPCIONES AL DERECHO DE AUTOR.................................................................. 22

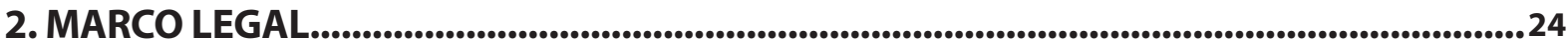

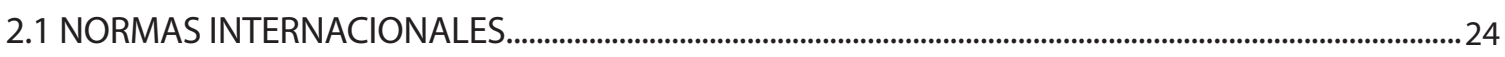

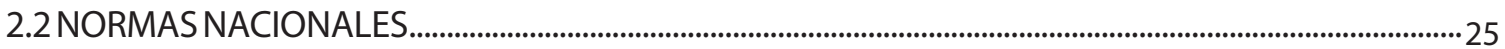

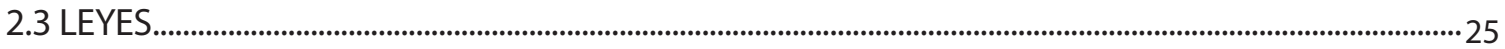

2.4 DECRETOS

3. POLÍTICA EDITORIAL UNIVERSIDAD DE BOYACÁ..........................................................................2 27

3.1 CARACTERÍSTICAS DE LA EDITORIAL UNIVERSIDAD DE BOYACÁ..............................................28

3.1.1 Derechos patrimoniales.............................................................................................................................. 28

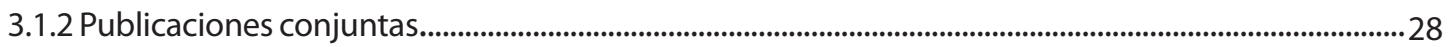

3.1.3 Normas éticas para las publicaciones..........................................................................................................2 29

3.1.4 Normas para autores........................................................................................................................................29

3.1.5 Normas para los pares evaluadores...........................................................................................................30

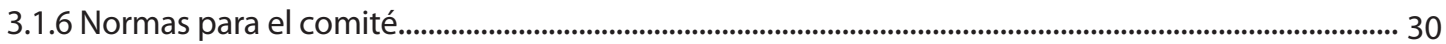

3.1.7 Normas para el editor..................................................................................................................................... 31

3.1.8 Cumplimiento de las normas por la Universidad de Boyacá..................................................................31

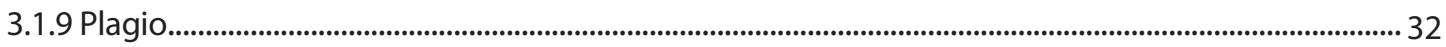


4. ESTRUCTURA ORGANIZACIONAL PARA EL CUMPLIMIENTO DE LA POLÍTICA EDITORIAL

4.1 ANTECEDENTES.

5. VISIÓN Y MISIÓN DE LA DIVISIÓN DE PUBLICACIONES.

5.1 VISIÓN.

5.2 MISIÓN.

6. OBJETIVOS Y FUNCIONES DE LA DIVISIÓN DE PUBLICACIONES.

6.1 OBJETIVO. 38

6.2 FUNCIONES SEGÚN ACUERDO 060 DEL 2012, DEL HONORABLE CONSEJO DE FUNDADORES ARTÍCULO DÉCIMO CUARTO..

\section{GESTIÓN EDITORIALY PUBLICACIÓN.}

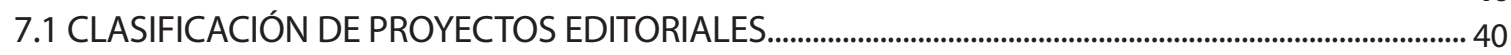

7.2 CRITERIOS DE PUBLICACIÓN...................................................................................................................42

7.3 DIRECTRICES DE PUBLICACIÓN..................................................................................................................4

7.4 MECANISMOS DE VISIBILIDAD Y ACCESIBILIDAD ...................................................................................45

8.COMUNICACIONES...................................................................................................................45

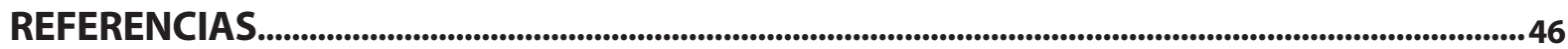




\section{TABLA DE ILUSTRACIONES}

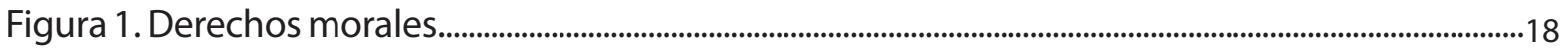

Figura 2. Derechos patrimoniales........................................................................................................................

Figura 3. Organigrama División de Publicaciones......................................................................................................35 


\section{Presentación}

La Universidad de Boyacá ha establecido como política que el producto de sus actividades académicas, investigativas y de proyección social, sea un libro, un artículo, maqueta, dibujo u otra expresión científica, cultural, artística, que sea publicado bajo la forma que corresponde y definido por las normas sobre publicaciones.

Para ello, las normas que debe cumplir la Universidad están enmarcadas dentro de las leyes establecidas sobre derechos de autor, derechos morales y derechos patrimoniales. En relación con los derechos de autor se explicitan sus derechos y las clases de obra que puede crear una persona natural, los términos de protección, así como las limitaciones y excepciones a que está sujeto.

Con el fin de dar cumplimiento a la publicación de todos los citados productos del trabajo de directivos, docentes, administrativos y estudiantes de la institución de forma más eficiente y obtener mayor visibilidad se creó la editorial "Ediciones Universidad de Boyacá".

La política editorial de la Universidad establecida mediante Acuerdo No. 1178 del 15 de noviembre de 2018, está implícita en el Programa Gestión Editorial de la Política de Investigación, Innovación y Divulgación del Conocimiento del Plan de Desarrollo, aprobado por el Consejo de Fundadores mediante Acuerdo No. 093 del 10 de diciembre de 2018, establece:

"Producir y divulgar material editorial, resultado del quehacer académico, investigativo, de proyección social y de extensión bajo parámetros de calidad científica y gráfica, siguiendo los estándares de editoriales, promoviendo e impulsando la publicación de proyectos editoriales individuales o colectivos en los diferentes campos del saber".

Para cumplir con esta política se constituyen las normas, acordes con las leyes nacionales, para el funcionamiento de la Editorial de la Universidad de Boyacá (Ediciones Universidad de Boyacá) y se crea un comité operativo mediante Acuerdo No. 1048 B del Consejo Directivo, 15 
de diciembre de 2017, con carácter asesor, evaluador y de seguimiento con el fin de "velar por la calidad académica y editorial de las publicaciones y para dar cumplimiento a los criterios de originalidad con principios éticos". Así mismo, la Resolución de Rectoría No. 037 del 08 de marzo de 2018 establece la composición del Comité Editorial con personal directivo del más alto nivel, con el fin de dar cumplimiento a las funciones allí establecidas y a las normas incluidas en el presente documento para todas las publicaciones institucionales.

Finalmente se hace un importante análisis de la estructura administrativa creada para cumplir con todas las políticas que a través del tiempo han emitido los órganos de dirección de la Universidad, de las funciones de cada profesional y la evolución de los resultados obtenidos.

Un gran agradecimiento a todos los miembros del Comité Editorial por su importante apoyo en la elaboración del presente Documento Institucional, especialmente a la Abogada Mónica Alexandra Álvarez por su coordinación y el estudio juicioso de la legislación y las formas de hacer más eficiente el trabajo editorial en la Universidad de Boyacá.

\title{
ROSITA CUERVO PAYERAS
}

\author{
Rectora
}




\section{MARCO CONCEPTUAL}

\subsection{Propiedad Intelectual}

La información o el conocimiento se avizoran en esta época como nuevas formas de riqueza que han producido un nuevo derecho, que es el Derecho de la Propiedad Intelectual, por encima del tradicional derecho de propiedad', el cual, se manifiesta a través del goce y disposición de una cosa material dentro de los límites legales; la propiedad intelectual se trata de un régimen jurídico que protege y defiende la propiedad inmaterial, incorporal e intangible.

Esta circunstancia de la transformación de la información o el conocimiento en un recurso fundamental para el ser humano es lo que ha hecho que la propiedad intelectual como disciplina normativa, proteja las creaciones intelectuales provenientes de un esfuerzo inteligible de la creatividad o destreza humana, dignos de reconocimiento jurídico.

De tal calidad participan las obras literarias, artísticas y científicas; los inventos y los signos distintivos mercantiles. Por lo tanto, la propiedad intelectual comprende, la Propiedad Industrial y el Derecho de Autor o "Copy Right" para los anglosajones. Es de anotar que el Derecho de Autor protege creaciones, independientemente de su aplicación industrial, esto es lo que lo diferencia de la Propiedad Industrial.

El poder jurídico que ostentan el autor o el inventor no es del género de la propiedad común, porque no puede existir una apropiación física como la que se manifiesta cuando se trata de cosas corporales; sin embargo, sobre el invento industrial, la obra literaria y la obra científica, se ejerce un señorío, de ahí que se hable de propiedad, pues en ellos se dan las características de la exclusividad y de la transmisibilidad.

1 Rojina (1985), plantea que la propiedad "se manifiesta en el poder jurídico que una persona ejerce en forma directa e inmediata sobre una cosa para aprovecharla totalmente en sentido jurídico, siendo oponible este poder a un sujeto pasivo universal por virtud de una relación que se origina entre el titular y dicho sujeto" (p. 38). 


\subsection{Derecho de Autor}

Los derechos de Propiedad Intelectual son derechos fundamentales de tercera generación, contemplados en el Pacto Internacional de Derechos Económicos, Sociales y Culturales de las Naciones Unidas, artículo 15 del 16 de diciembre de 1966.

En materia del Derecho de Autor, el principal instrumento internacional para la protección de las obras literarias, científicas y artísticas es el Convenio de Berna del 9 de septiembre de $1886^{2}$, administrado por la Organización Mundial de la Propiedad Intelectual [OMPI], que en su artículo $2^{\circ}$, numeral primero, establece que:

1) Los términos «obras literarias y artísticas» comprenden todas las producciones en el campo literario, científico y artístico, cualquiera que sea el modo o forma de expresión, tales como los libros, folletos y otros escritos; las conferencias, alocuciones, sermones y otras obras de la misma naturaleza; las obras dramáticas o dramático-musicales; las obras coreográficas y las pantomimas; las composiciones musicales con o sin letra; las obras cinematográficas, a las cuales se asimilan las obras expresadas por procedimiento análogo a la cinematografía; las obras de dibujo, pintura, arquitectura, escultura, grabado, litografía; las obras fotográficas a las cuales se asimilan las expresadas por procedimiento análogo a la fotografía; las obras de artes aplicadas; las ilustraciones, mapas, planos, croquis y obras plásticas relativas a la geografía, a la topografía, a la arquitectura o a las ciencias (p. 3).

En concordancia con estos preceptos normativos, el Congreso de la República expidió la Ley 23 de 1982, como conjunto de facultades que protegen los derechos morales y patrimoniales de los creadores de obras literarias, artísticas o científicas, así como los derechos conexos de los artistas, intérpretes o ejecutantes, los productores de fonogramas, organismos de radiodifusión; es decir, dicha norma soporta la relación jurídica que subyace al autor con su creación intelectual y la forma legítima en que la sociedad puede hacer uso de ella.

$2 \quad$ Adoptado por Colombia 101 años después con la Ley 33 de 1987.

14 
Al respecto, tratadistas como Olarte \& Rojas (2010) consideran que: "A partir del anterior mandato constitucional encontramos en nuestro ordenamiento jurídico todo un desarrollo legal y reglamentario consagrando la protección a la propiedad intelectual en sus dos vertientes: El derecho de autor y la propiedad industrial" (p. 8).

En tal sentido, el artículo $2^{\circ}$ de la Ley 23 de 1982 establece que:

Los derechos de autor recaen sobre las obras científicas, literarias y artísticas en las cuales se comprenden todas las creaciones del espíritu en el campo científico, literario y artístico, cualquiera que sea el modo o forma de expresión y cualquiera que sea su destinación, tales como: los libros, folletos y otros escritos; las conferencias, alocuciones, sermones y otras obras de la misma naturaleza; las obras dramáticas o dramático musicales; las obras coreográficas y las pantomimas; las composiciones musicales con letra o sin ella; las obras cinematográficas, a las cuales se asimilan las obras expresadas por procedimiento análogo a la cinematografía, inclusive los videogramas; las obras de dibujo, pintura, arquitectura, escultura, grabado, litografía; las obras fotográficas a las cuales se asimilan las expresadas por procedimiento análogo a la fotografía; las obras de arte aplicadas; las ilustraciones, mapas, planos, croquis y obras plásticas relativas a la geografía, a la topografía, a la arquitectura o a las ciencias, y, en fin, toda producción del dominio científico, literario o artístico que pueda reproducirse, o definirse por cualquier forma de impresión o de reproducción, por fonografía, radiotelefonía o cualquier otro medio conocido o por conocer.

Los derechos de autor se reputan de interés social y son preferentes a los de los intérpretes o ejecutantes, de los productores de fonogramas y de los organismos de radiodifusión, y en caso de conflicto primarán los derechos del autor (pp. 2 - 3).

Esta protección jurídica beneficia al autor y a sus derechohabientes, entiéndase por tales los causahabientes ${ }^{3}$ y los mortis causa ${ }^{4}$.

Así mismo, es igual de importante el Tratado de la Organización Mundial de Propiedad Intelectual (OMPI) sobre Derecho de Autor [WCT], aprobado por Colombia mediante la Ley 565

3 Persona natural o jurídica a quien contractualmente se le concede jurídicamente la explotación patrimonial de la obra.

4 Los herederos del titular de la obra, ya sea a título singular o universal. 
de 2000, el cual en su artículo $2^{\circ}$, establece que el ámbito de protección del Derecho de Autor "abarcará las expresiones, pero no las ideas, procedimientos, métodos de operación o conceptos matemáticos en sí" (p. 2); además, concede las prerrogativas a las partes que lleguen a contratar en torno a ellos, en ejercicio de la autonomía, la voluntad y la aplicación de mutatis mutandis, de las disposiciones de los artículos 2 al 6 del Convenio de Berna respecto de la protección contemplada en el Tratado de la OMPI sobre Derecho de Autor [WCT].

Por su parte, el derecho comunitario el cual es norma prevalente sobre el derecho interno y tiene aplicación inmediata por regla general, regula el Derecho de Autor, en la Decisión 351 de la Comisión de la Comunidad Andina de 1993. Igualmente, ambos derechos se encuentran regulados en el artículo 61 de la Carta Política Colombiana que in extenso establece que, "El Estado protegerá la propiedad intelectual por el tiempo y mediante las formalidades que establezca la ley" (p. 28).

\subsection{Derechos inherentes al Derecho de Autor}

El autor de una obra, con la sola expresión de sus ideas, es merecedor de dos clases de prerrogativas en el ámbito jurídico de la propiedad intelectual, las cuales se conocen como derechos morales o extrapatrimoniales de autor y derechos patrimoniales de autor.

\subsection{Derechos morales}

Estos derechos regulan la relación jurídica del autor con la obra y le confieren a este facultades personalísimas, intransferibles, perpetuas, imprescriptibles, inembargables, las cuales se encuentran consagradas en el artículo 11 de la Decisión 351 de la Comunidad Andina de 1993; estos derechos, a pesar de la cesión de los derechos patrimoniales por parte del autor, se conservan y no se pueden ceder. Al respecto, se ha señalado que "los derechos morales son independientes y nunca se presumen o se entienden cedidos" (Caballero, 2004, p. 8).

Los derechos morales, según la legislación vigente, son cinco (Ley 23, 1982):

a. El derecho de la paternidad: consiste en la facultad que tiene el autor de aparecer como creador, como padre de la obra, así no tenga su explotación económica. Al 
respecto, señala la Ley 23 de 1982 en su artículo 30, literal a) “Reivindicar en todo tiempo la paternidad de su obra y, en especial, para que se indique su nombre o seudónimo cuando se realice cualquiera de los actos mencionados en el artículo 12 de esta ley" (p. 11), es decir, su reproducción, traducción, adaptación, un arreglo u otra transformación de la obra, y cuando se comunica la obra al público mediante representación, ejecución, radiodifusión o cualquier otro medio que permita su comunicación.

b. Derecho de la integridad de la obra: se refiere a la prerrogativa que se radica en cabeza del autor y que consiste en la oposición que este puede ejercer respecto de la deformación, mutilación o modificación que cause un perjuicio al honor o reputación del autor o que la obra se demerite por tal modificación $n^{5}$.

c. Derecho de ineditud y/o anonimato: esta exención la puede ejercer el creador de una obra durante su vida, incluso hasta su fallecimiento o después de él, cuando así lo ordenara por disposición testamentaria; consiste en la facultad que tiene para que su obra no sea publicada o para que su nombre se conserve de forma anónima y reservada.

d. Derecho al arrepentimiento: consiste en el arrepentimiento de la obra por parte de su autor; se puede retirar la obra inclusive cuando ya está en circulación.

e. Derecho a la modificación: consiste en la prerrogativa que tiene el autor de realizar cambios a la obra, inclusive cuando ya está publicada.

Los dos últimos derechos solo se pueden ejercer a cambio de la indemnización de perjuicios.

La defensa de la paternidad, integridad y autenticidad de las obras a la muerte del autor le corresponde a su cónyuge y herederos; cuando la obra científica, artística o literaria haya pasado al dominio público, los derechos morales estarán a cargo del Ministerio de Cultura, siempre y cuando tales obras no tengan titulares o causahabientes que puedan defender o tutelar estos derechos morales, así lo ha establecido la legislación.

$5 \quad \mathrm{Al}$ respecto, el literal B del artículo 30 de la Ley 23 de 1982, señala que el autor tiene derecho "A oponerse a toda deformación, mutilación u otra modificación de la obra, cuando tales actos puedan causar o acusen perjuicio a su honor o a su reputación, o la obra se demerite, y a pedir reparación por esto" (p. 11). 
Figura 1. Derechos morales



Fuente: adaptado de Rey, (2005). La Propiedad Intelectual como Bien Inmaterial. p. 28

\subsection{Derechos patrimoniales}

Hacen referencia a las prerrogativas que se le confieren al titular de la obra literaria, científica o artística, sea persona natural o jurídica. Estas prerrogativas se encuentran reguladas por el artículo 13 y subsiguientes, de la Decisión $351^{6}$ de 1993, consisten en el derecho exclusivo de realizar o de autorizar la reproducción, distribución, transformación y comunicación al público de la obra.

6 Artículo 13.- El autor o, en su caso, sus derechohabientes, tienen el derecho exclusivo de realizar, autorizar o prohibir:

a) La reproducción de la obra por cualquier forma o procedimiento;

b) la comunicación pública de la obra por cualquier medio que sirva para difundir las palabras, los signos, los sonidos o las imágenes;

c) la distribución pública de ejemplares o copias de la obra mediante la venta, arrendamiento o alquiler;

d) la importación al territorio de cualquier país miembro de copias hechas sin autorización del titular del derecho;

e) la traducción, adaptación, arreglo u otra transformación (Decisión 351, 1993, p. 5). 
Figura 2. Derechos patrimoniales

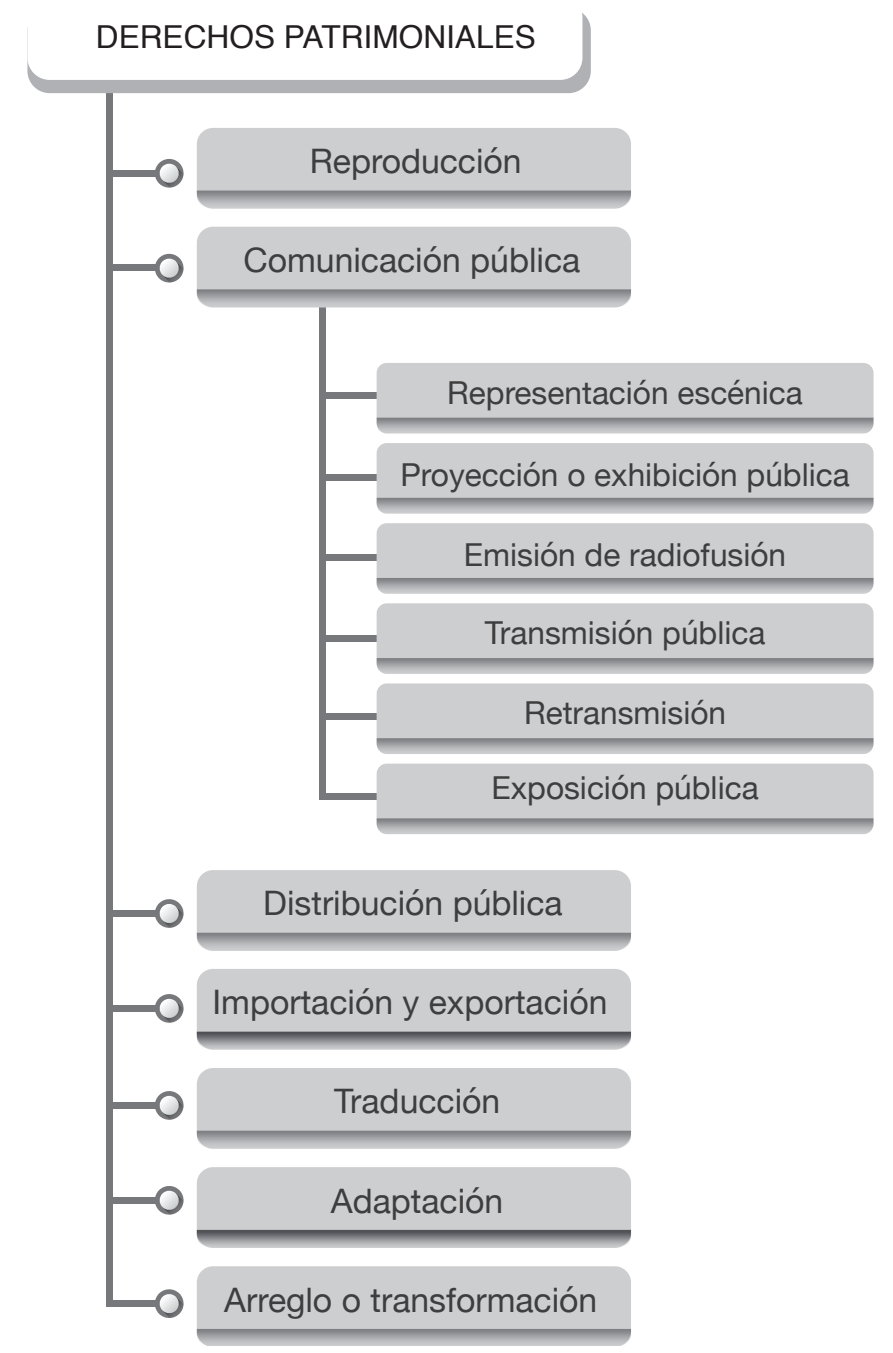

Fuente: adaptado Rey, (2005). La Propiedad Intelectual como Bien Inmaterial. p. 28 


\subsection{Objeto de protección de Derecho de Autor}

Corresponde a un bien inmaterial, a la creación intelectual de carácter original que se denomina obra, es decir, aquella idea producto del ingenio humano que ha sido exteriorizada y fijada en algún soporte material; al respecto, "Satanowsky considera que la obra intelectual debe ser la expresión, personal, perceptible, original y novedosa de la inteligencia, resultado de la actividad del espíritu, que tenga individualidad, que sea completa y unitaria y que sea una creación integral" (Rangel,1992, p. 91).

Las obras objeto de protección del Derecho de Autor son las literarias, científicas y artísticas, a la luz de lo preceptuado por el artículo 2 de la Ley 23 de 1982.

\subsection{Sujetos de Derecho de Autor}

Autor: en el derecho colombiano, el autor siempre es una persona natural que crea alguna obra literaria, científica o artística y que la fija en algún soporte material, por ejemplo, en un escrito o alocución; para ostentar tal calidad, no se requiere cumplir alguna formalidad jurídica o algún trámite administrativo, pues su registro es meramente declarativo de derecho y no constitutivo.

Al respecto señala Rey (2005), que para adquirir tal condición no se requiere el cumplimiento de requisito, ni formalidad legal alguna.

En el supuesto en que surjan dudas, se presumirá autor a quien aparezca como tal en la obra, mediante su nombre, firma o signo que lo identifique. De no ser así, cuando estemos en presencia de obras anónimas o firmadas o protegidas por un seudónimo, los derechos de carácter personal y patrimonial inherentes a la condición de autor serán ejercidos por la persona natural o jurídica que saque a la luz la obra con el consentimiento del autor real (p. 35).

Titular: puede recaer en persona natural o persona jurídica; existen dos clases de titular de la obra a saber:

- Titular originario: es el autor o coautor que creó la obra científica, literaria o artística. 
- Titular derivado: es la persona natural o jurídica a quien se le transfirió de manera total o parcial la obra científica, literaria o artística.

Presunción de autoría: la legislación colombiana, en consonancia con la distinción entre autoría y titularidad, establece una presunción de autoría que admite prueba en contrario, en cambio, no se admite presunción de titularidad ${ }^{7}$.

Quien alegue que es el verdadero autor, tiene que desvirtuar la presunción del artículo 10 de la Ley 23 de 1982.

\subsection{Clases de obras según la ley de Derecho de Autor ${ }^{8}$}

Individual: creada por una sola persona natural, que realiza alguna obra literaria, científica o artística y que la fija en algún soporte material.

Obra en colaboración: producida conjuntamente por dos o más personas naturales, cuyos aportes no puedan ser separados. Para que haya colaboración, no basta con que la obra sea trabajo de varios colaboradores, es preciso además que la titularidad del derecho de autor no pueda dividirse sin alterar la naturaleza de la obra, se predica de ella la misma figura de la comunidad en derecho.

Obra colectiva: la que se produce por un grupo de autores, por iniciativa y bajo la orientación de una persona natural o jurídica, que la coordine, publique y divulgue bajo su nombre y riesgo. Los colaboradores son los titulares de los derechos morales, pero los patrimoniales son de la persona que ha asumido el riesgo de la creación.

7 Ley 23 de 1982. Artículo 10.- Se tendrá como autor de una obra, salvo prueba en contrario, la persona cuyo nombre, seudónimo, iniciales o cualquier otra marca o signos convencionales que sean notoriamente conocidos como equivalentes al mismo nombre, aparezcan impresos en dicha obra o en sus reproducciones, o se enuncien en la declamación, ejecución, representación, interpretación o cualquiera otra forma de difusión pública de dicha obra (p. 6).

$8 \quad$ Según artículo 8 de la Ley 23 de 1982. 


\subsection{Término de protección}

Se establece que el término de protección de Derecho de Autor será durante la vida del autor y 80 años más, cuando es persona natural, contados a partir del 1 de enero del año siguiente a su muerte; en caso de obra en colaboración debidamente establecida, el término de ochenta años se contará desde la muerte del último coautor.

Cuando el titular del derecho de autor sea una persona jurídica, el plazo de protección será de 70 años contados a partir del final del año calendario de la primera publicación autorizada de la obra.

\subsection{Limitaciones y excepciones al Derecho de Autor}

El Derecho de Autor, con el fin de mantener un punto de equilibrio entre los intereses morales y patrimoniales del autor y el interés supraindividual o interés público en general, estableció unas excepciones legales a las facultades de autorizar y prohibir que concede el Derecho de Autor, las cuales fueron decantadas taxativamente por el legislador, ${ }^{9}$ circunscribiéndose a casos especiales cuando se presenten estos eventos; su uso no requiere la previa y expresa autorización del autor, de su derechohabiente o de su causahabiente.

Estas limitaciones o excepciones del Derecho de Autor son:

- Se permite referenciar a un autor transcribiendo las citas necesarias, siempre que estas no se repitan mucho ni estén muy seguidas, hasta el extremo en que razonadamente puedan considerarse como una reproducción simulada y sustancial, que redunde en perjuicio del autor de la obra de donde se toman. En cada cita deberá mencionarse el nombre del autor de la obra citada y el título de dicha obra.

9 Estas disposiciones están fijadas en la Ley 23 de 1982, artículos 31 al 44. 
- Se pueden utilizar o comunicar obras científicas, literarias o artísticas o parte de ellas, a título de enseñanza y/o para fines escolares, educativos, universitarios y de formación profesional sin fines de lucro, con la obligación de mencionar el nombre del autor y el título de las obras así utilizadas por medio de publicaciones, emisiones de radiodifusión o grabaciones sonoras o visuales, dentro de los límites justificados por el fin propuesto, o comunicar con propósitos de enseñanza la obra radiodifundida.

- Es lícito reproducir, distribuir, comunicar las noticias o hechos notorios producidos por los medios de comunicación; estos podrán publicar los discursos pronunciados o leídos en asambleas deliberantes, en los debates judiciales, en los espacios en los que se promuevan ante otras autoridades públicas o en cualquier conferencia, discurso, sermón u otra obra similar, pronunciada en público, siempre que se trate de obras cuya propiedad no haya sido, previa y expresamente, reservada; igualmente, que su difusión no haya sido prohibida por cualquier medio.

- La publicación de retratos o fotografías es libre cuando se relaciona con fines científicos, didácticos o culturales en general, o con hechos o acontecimientos de interés público o que se hubieren desarrollado en público, salvo que se trate de menores de edad.

- Las bibliotecas públicas pueden reproducir para el uso exclusivo de sus lectores, y cuando ello sea necesario para su conservación o para el servicio de préstamos a otras bibliotecas también públicas, una copia de obras protegidas depositadas en sus colecciones o archivos que se encuentren agotadas en el mercado local.

- Será permitido reproducir por medio de pinturas, dibujos, fotografías o películas cinematográficas, las obras que estén colocadas de modo permanente en vías públicas, calles o plazas; asimismo, se podrán distribuir y comunicar públicamente dichas reproducciones u obras. En lo que se refiere a las obras de arquitectura, esta disposición legal solo es aplicable a su aspecto exterior.

- Las conferencias o lecciones dictadas en establecimiento de enseñanza superior, secundaria o primaria pueden ser anotadas y recogidas libremente por los estudiantes 
a quienes están dirigidas, pero es prohibida su publicación o reproducción integral o parcial, sin la autorización escrita de quien las pronunció.

- Es permitido a todos reproducir la Constitución Nacional, leyes, decretos, ordenanzas, acuerdos, reglamentos, demás actos administrativos y decisiones judiciales, bajo la obligación de conformarse puntualmente con la edición oficial, siempre y cuando no esté prohibido.

- Es permitida la reproducción de obras protegidas o de fragmentos de ellas, en la medida que se estime necesaria por la autoridad competente, para su uso dentro de los procesos judiciales o por los órganos legislativos o administrativos del Estado.

- El autor de un proyecto arquitectónico no podrá impedir que el propietario introduzca modificaciones en dicho proyecto, pero tendrá la facultad de prohibir que su nombre sea asociado a la obra alterada.

- Es libre la utilización de obras científicas, literarias y artísticas en el domicilio privado sin ánimo de lucro.

\section{MARCO LEGAL}

\subsection{Normas Internacionales}

- Tratado de la Organización Mundial de la Propiedad Intelectual (OMPI) sobre Derecho de Autor, adoptado por la Conferencia Diplomática el 20 de diciembre de 1996, aprobado por la Ley 565 de 2000.

- Tratado de la Organización Mundial de la Propiedad Intelectual (OMPI) sobre Derecho de Autor, adoptado por la Conferencia Diplomática el 20 de diciembre de 1996, aprobado por la Ley 565 de 2000. 
- Convenio de Berna del 9 de septiembre de 1886, el cual se creó para la Protección de las Obras Literarias y Artísticas, aprobado por la Ley 33 de 1987.

- Decisión Andina 351 de 1993, se aprueba el Régimen Común sobre Derecho de Autor y Derechos Conexos.

- Pacto Internacional de Derechos Económicos, Sociales y Culturales de las Naciones Unidas, los derechos sobre propiedad intelectual son considerados como derechos fundamentales de tercera generación, entra en vigencia para Colombia con la Ley 74 de 1.976 .

\subsection{Normas Nacionales}

\section{Constitución Política de Colombia}

Artículo 61: "El Estado protegerá la propiedad intelectual por el tiempo y mediante las formalidades que establezca la ley" (p. 28).

Artículo 150. Mediante el cual se establece que "Corresponde al Congreso hacer las leyes. Por medio de ellas ejerce las siguientes funciones:... .24. Regular el régimen de propiedad industrial, patentes y marcas y las otras formas de propiedad intelectual" (p. 52).

\subsection{Leyes}

- Ley 1915 del 12 de julio de 2018, por la cual se modifica la ley 23 de 1982 y se establecen otras disposiciones en materia de Derecho de Autor y Derechos Conexos.

- Ley 1834 del 23 de mayo de 2017, por medio de la cual se fomenta la economía creativa.

- Ley 1712 del 6 de marzo de 2014, mediante la cual se crea la ley de transparencia y del derecho de acceso a la información pública. 
- Ley 1379 del 15 de enero de 2010, a través de la cual se define la política de la Red Nacional de Bibliotecas Públicas, se regula su funcionamiento y se establecen instrumentos para su desarrollo integral y sostenible.

- Ley 599 del 24 de julio de 2000, por la cual se expide el Código Penal Art. 257, 270, 271 y 272.

- Ley 44 del 5 de febrero de 1993 por la cual se modifica y adiciona la Ley 23 de 1982 y se modifica la Ley 29 de 1944.

- Ley 23 del 28 de enero de 1982 sobre Derechos de Autor.

\subsection{Decretos}

- Decreto 1162 de abril 13 de 2010, organiza el Sistema Administrativo Nacional de Propiedad Intelectual y se crea la Comisión Intersectorial de Propiedad Intelectual.

- Decreto 0162 del 22 de enero de 1996, reglamenta la Decisión Andina No. 351 de 1993 y la Ley 44 de 1993 en relación con las Sociedades de Gestión Colectiva de Derecho de Autor o de Derechos Conexos.

- Decreto 460 del 16 de marzo de 1995. Reglamentación del Registro Nacional del Derecho de Autor y Regulación del Depósito Legal. 


\section{POLÍTICA EDITORIAL UNIVERSIDAD DE BOYACÁ}

El Acuerdo 1178 del 15 de noviembre de 2018, emanado del Honorable Consejo Directivo, estableció la Política Editorial de la Universidad de Boyacá conforme a los referentes misionales y visionales de la Institución, la cual favorece el desarrollo de la Política de Investigación, Innovación y Divulgación del Conocimiento, de la cual se deriva el Programa Gestión Editorial, que incluye los proyectos de Fortalecimiento de la Producción Editorial y Visibilización de la Producción Editorial, decantados en el Plan de Desarrollo Institucional Acuerdo 093 del 10 de diciembre de 2018 del Consejo de Fundadores. La política editorial in extenso establece: "Producir y divulgar material editorial, resultado del quehacer académico, investigativo, de proyección social y de extensión bajo parámetros de calidad científica y gráfica siguiendo los estándares de editoriales, promoviendo e impulsando la publicación de proyectos editoriales individuales o colectivos en los diferentes campos del saber".

Todo lo anterior a fin de exhortar y motivar a los investigadores de los diferentes estamentos a la generación y apropiación de conocimiento en los diferentes campos del saber, fortaleciendo el desarrollo institucional y científico, resultado de procesos investigativos, de proyección social, pedagógicos, didácticos y tecnológicos que respondan a las necesidades del contexto.

Este propósito ha acompañado el proceder de la Institución desde sus inicios, ante las necesidades de visibilizar la producción escrita y visual de la comunidad académica y administrativa. En el año 1984 se crea la División de Producción de Materiales, la cual respondía a la transformación que las necesidades y los planes de desarrollo demandaban; actualmente se denomina División de Publicaciones, encargada de administrar el sello editorial y gestionar la producción y difusión de material editorial derivado de las actividades investigativas, académicas, de proyección social y de extensión, así mismo, de experiencias y prácticas educativas de los docentes, estudiantes e investigadores. La División gestiona publicaciones con un alcance científico, socio-económico, artístico, cultural y pedagógico que aportan a la transformación del conocimiento y el entorno y generan impacto a nivel local, regional, nacional e internacional.

La editorial publica los proyectos editoriales de la comunidad académica y científica en medio impreso y/o digital. Por consiguiente, para llegar a este punto, la propiedad intelectual de los 
docentes se protege con los requerimientos planteados en la Política Editorial que favorece, entre otros aspectos, un riguroso proceso de evaluación por pares, garantizando la calidad científica y editorial; de igual manera, la editorial difunde, visibiliza y pone en circulación la producción intelectual a través de distribuidores, página web y portal de revistas digitales, para llegar al público en general.

Esta política ofrece a la comunidad un acompañamiento y guía sobre los lineamientos o directrices para la presentación de los proyectos editoriales, su selección, evaluación y publicación, suministrando material fundamental para su cumplimiento.

\subsection{Características de la Editorial Universidad de Boyacá}

\subsubsection{Derechos patrimoniales}

El contenido de los proyectos editoriales de la Editorial de la Universidad de Boyacá y sus características gráficas son de propiedad exclusiva de la Universidad de Boyacá. En dichos proyectos se incluyen las obras científicas, literarias, artísticas y en general, todas las producidas por docentes, investigadores, funcionarios y estudiantes; editadas y/o publicadas bajo el sello editorial de la Universidad de Boyacá, ya sea de forma impresa y/o digital. Los derechos patrimoniales comprometidos en la reproducción, transformación, comunicación pública, comercialización, distribución y demás actividades que involucren dichas obras, son cedidos por los autores, compiladores o editores mediante la firma del contrato laboral y/o la firma del formato de declaración de originalidad, garantías y cesión de derechos patrimoniales. Los autores solo conservarán los derechos morales de su obra, por lo tanto, está prohibido todo tipo de reproducción e intervención anteriormente nombrada en este apartado, sin consentimiento del titular.

\subsubsection{Publicaciones conjuntas}

En las publicaciones conjuntas se deben considerar los términos en los cuales participa la Universidad de Boyacá, en caso de coedición con otras instituciones; para tal fin, se diligenciará un contrato de coedición donde se estipulen las cláusulas que den cuenta del editor y coeditor, 
autorías, aportes financieros, distribución, comercialización de los libros y pago de regalías a los autores.

\subsubsection{Normas éticas para las publicaciones}

Las publicaciones se acogen a las directrices estipuladas en la Política Editorial de la Universidad de Boyacá; a los estándares internacionales para la publicación científica responsable, descritos en la 2nd World Conference on Research Integrity; a las buenas prácticas editoriales instauradas por el código de conducta de publicaciones científicas Committe on Publication Ethics [COPE]; y a lo establecido en la Ley Estatutaria 1266 de 2008, en la cual se dictan disposiciones generales del Habeas Data, para el manejo de información personal en bases de datos.

A continuación, se presentan las normas de conducta ética para los involucrados en el proceso editorial:

\subsubsection{Normas para autores}

Todo manuscrito postulado para publicación pasará por un riguroso proceso editorial de revisión por parte de pares evaluadores, cumpliendo con las directrices y política.

Así mismo, los manuscritos deben tener una pertinencia académico-investigativa, que genere aportes e impacto en el contexto y los diferentes campos del saber, garantizando la originalidad y la rigurosidad del proceso investigativo contenido en los soportes de análisis presentados en el documento. No se considerará original un trabajo que sea traducido de otro idioma.

Además, para evitar un conflicto de intereses, los postulantes deben garantizar que todos aquellos que hicieron aportes significativos a la publicación figuren como autores; no deben aparecer como autores personas que no participaron en el proceso.

Los autores deben firmar una declaración de originalidad y carácter inédito de la obra, con la cual dan fe de que esta no se ha publicado ni postulado en otro medio de difusión impreso o 
electrónico; a la vez, certifican que las ideas de otros autores expuestas en el escrito se encuentran debidamente citadas.

\subsubsection{Normas para los pares evaluadores}

Los pares evaluadores son investigadores reconocidos por su trayectoria académico-investigativa, asignados por la Vicerrectoría de Investigación Ciencia y Tecnología de acuerdo a su especialidad; estos se comprometen a mantener la confidencialidad de la información que se les suministra y su función será exclusivamente evaluativa. No se les autoriza ni el uso ni la difusión de los textos sin publicar, estos solo se podrán citar cuando estén publicados. Al divulgar o publicar esta información, parcial o totalmente, incurrirán en una práctica inadecuada y no autorizada, exponiéndose a la consiguiente sanción.

Los pares deben comprometerse a evaluar el documento en los tiempos establecidos por la Vicerrectoría de Investigación Ciencia y Tecnología, como también, a informar la disponibilidad de su agenda para cumplir con el proceso evaluativo, atendiendo los parámetros de rigor según la tipología del libro que se encuentran en los formatos de evaluación.

\subsubsection{Normas para el comité}

El Comité Editorial se creó mediante Acuerdo 1048 B del Honorable Consejo Directivo de la Universidad de Boyacá. Mediante Resolución No. 037 del 8 de marzo de 2018, se estableció que el Comité Editorial estaría presidido por el Rector (a) o su delegado y lo integrarían:

- El Vicerrector de Investigación Ciencia y Tecnología.

- El Director del Centro de Investigaciones para el Desarrollo - CIPADE.

- El Director de la División de Publicaciones. 
Así mismo, sus funciones consisten en:

1. Direccionar las estrategias para el cumplimiento de la política editorial.

2. Evaluar y estudiar en conjunto la publicación de los proyectos editoriales de la Universidad.

3. Proponer los criterios de evaluación de las publicaciones.

4. Aprobar o rechazar la publicación de los textos sometidos a su conocimiento.

5. Velar por la calidad de los proyectos editoriales y el buen manejo de la imagen del sello editorial.

En este orden de ideas, el Comité Editorial es el responsable de asegurar y velar por la calidad académica y editorial, decidir cuando se presentan conceptos divididos y evaluar la pertinencia de las publicaciones. De igual forma, debe propender por el cumplimiento de los criterios de originalidad y consideraciones éticas de la publicación, además, gestionar la edición y publicación en los tiempos establecidos y garantizar la imparcialidad en la evaluación de los manuscritos propuestos para su publicación, conservando la confidencialidad de su contenido hasta su aprobación o rechazo.

\subsubsection{Normas para el editor}

El editor es la persona responsable de la transparencia y calidad editorial de las obras; verifica el cumplimiento de las normas y políticas por parte de cada uno de los involucrados en el proceso editorial.

\subsubsection{Cumplimiento de las normas por la Universidad de Boyacá}

Ediciones Universidad de Boyacá, en cumplimiento de la normatividad del depósito legal, envía copia de sus ejemplares impresos, en la cantidad y en los plazos fijados por la Ley 44 de 1993, 
el Decreto 460 de 1995 y la Ley 1379 de 2010, a las entidades requeridas para garantizar su conservación.

\subsubsection{Plagio}

Si durante el proceso editorial de una obra se presenta omisión de datos, falsificación o plagio, esta será retirada del banco de publicaciones de la División de Publicaciones y se devolverá a los autores, explicándoles los motivos de su devolución y la respectiva sanción si son sujetos disciplinables de la Universidad de Boyacá; todo lo anterior con copia a la editorial afectada para que inicie el proceso legal a que haya lugar. Para prevenir el plagio o la duplicidad, las publicaciones radicadas serán revisadas internamente mediante herramientas "antiplagio".

\subsubsection{Conflicto de intereses}

En caso de presentarse un conflicto de intereses entre autores, editores o pares lectores, por la existencia de alguna relación explícita ya sea comercial, institucional, personal, académica o financiera que pueda incidir en la evaluación y/o publicación, los involucrados deben informar antes de iniciar cualquier proceso, al Comité Editorial, el cual tomará las respectivas decisiones para solucionar el impase.

El comité no iniciará ningún proceso editorial en los casos en que se presenten conflictos de intereses mientras que el percance se mantenga; si no se llega a un acuerdo, el texto será retirado del proceso editorial.

\subsubsection{Sanciones}

Cualquier falta a los criterios estipulados en la Política Editorial, será considerada por el Comité Editorial como una conducta inapropiada que acarreará una sanción, según los siguientes criterios $^{10}$ :

10 Tomando como referencia las sanciones establecidas por el (COPE).

32 
- Una carta de aclaración dirigida al autor(es), cuando parezca haber un malentendido de principios.

- Una carta de amonestación y advertencia para conductas futuras.

- Una carta formal al rector(a) de la institución, informando el hecho para establecer el tipo de sanción a que haya lugar.

- No recibir documentos futuros del autor(es).

- En el caso de que ya se encuentre publicado el libro y resulte que incurrió en plagio, la Universidad lo retirará de circulación y el autor(es) responderá(n) por el daño emergente y lucro cesante que ocasione con su actuar.

Sin perjuicio de las demás acciones disciplinarias contempladas en el Reglamento Interno de Trabajo y en el Reglamento de Personal Docente de la Universidad de Boyacá y demás sanciones legales a las que haya lugar.

\section{ESTRUCTURA ORGANIZACIONAL PARA EL CUMPLIMIENTO DE LA POLÍTICA EDITORIAL}

\subsection{Antecedentes}

Con la fundación de la Corporación de Educación Superior en 1979 en la ciudad de Tunja y ante la necesidad de visibilizar la producción escrita y visual de la comunidad académica y administrativa, el 28 de enero de 1984 se crea la División de Producción de Materiales, a cargo de la Vicerrectoría Operativa, según Acuerdo 039 del Honorable Consejo Directivo, por el cual se adopta la Estructura Orgánica y se determinan las funciones de sus dependencias.

Posteriormente, en el año de 1989, la Fundación adopta una nueva Estructura Orgánica, producto de varias modificaciones derivadas de las necesidades y los planes de desarrollo; en 
esa estructura se estableció un orden jerárquico, donde la División de Producción de Materiales se constituyó en la dependencia de Divulgación y Publicaciones, quedando a cargo de la Rectoría.

Con el surgimiento de nuevos programas de formación profesional de pregrado, posgrado y educación permanente, según el Acuerdo 148 del año 1991, la Universidad requirió actualizar la estructura orgánica académica y administrativa, razón por la cual se hicieron varias modificaciones; sin embargo, la dependencia de Divulgación y Publicaciones conservó su ubicación jerárquica.

Durante el periodo de 2002 - 2005, a partir del Acuerdo 335 del primero de marzo de 2002, se hace necesario ajustar la organización administrativa de la Institución, al igual que las actividades de las dependencias, debido al desarrollo científico, académico, tecnológico e investigativo. En relación con lo anterior, se crea el Centro de Investigación para el Desarrollo - CIPADE, del cual se desprenderá la Oficina de Publicaciones, anteriormente conocida como Divulgación y Publicaciones.

Mediante Acta de Constitución del 19 de abril de 2007, se establece el sello editorial denominado Ediciones Universidad de Boyacá, adscrito a la Vicerrectoría de Investigación Ciencia y Tecnología, al cual se le asignan unas funciones y una estructura administrativa conformada por Rectoría, Vicerrectoría de Investigación Ciencia y Tecnología, Editor en Jefe, Comité Editorial y la Oficina de Publicaciones.

En el año 2012 el Consejo de Fundadores promulga el Acuerdo 060 del 12 de marzo el cual, en su artículo décimo cuarto, concibe la División de Publicaciones y sus funciones, vinculada a la Vicerrectoría de Investigación Ciencia y Tecnológica.

Actualmente la estructura orgánica de la División de Publicaciones y Ediciones Universidad de Boyacá está constituida de la siguiente manera: 
Figura 3. Organigrama División de Publicaciones

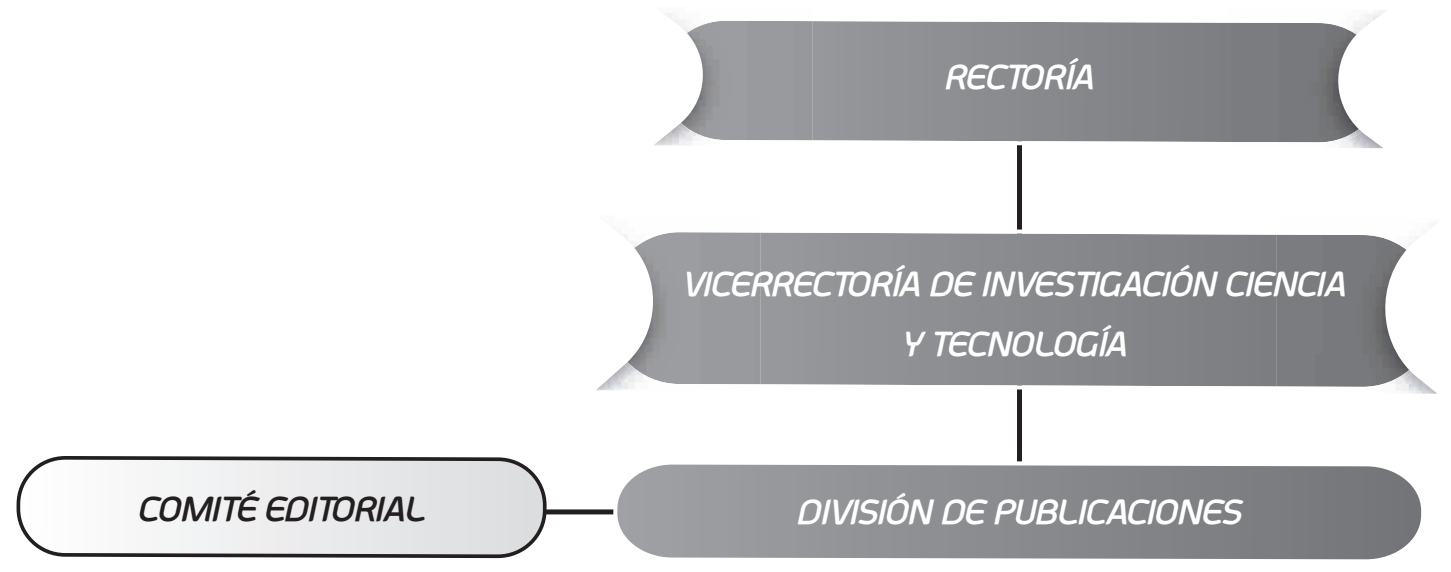

Fuente: Universidad de Boyacá

Rectoría: establece y da guías para las publicaciones de la Universidad y presenta los productos editoriales a la comunidad universitaria y a la sociedad.

Vicerrectoría de Investigación Ciencia y Tecnología: dirige y gestiona la producción escritural científica.

División de Publicaciones: administra el sello editorial de la Universidad de Boyacá; además, produce y divulga el material editorial resultado de procesos académicos, investigativos, de proyección social y de extensión, bajo parámetros de calidad científica y gráfica, siguiendo estándares editoriales.

Director de la División de Publicaciones: gestiona y promueve el proceso editorial de la Universidad de Boyacá. 
Funciones del Director:

- Consolidar la producción editorial de la Universidad con altos estándares de calidad académica e investigativa.

- Coordinar las funciones editoriales de la Universidad de Boyacá, con el fin de posibilitar la publicación de productos académicos, de investigación, de proyección social y de extensión.

- Gestionar y publicar libros y revistas que procuren la visibilidad y difusión del conocimiento ante la comunidad universitaria y la sociedad.

- Divulgar, gestionar y distribuir las publicaciones de la universidad, las cuales circulan a nivel regional, nacional e internacional y potenciar el impacto de la institución en el ámbito académico e investigativo.

- Realizar los trámites de registro y legalización de los libros y revistas ante las diferentes entidades gubernamentales.

- Verificar la calidad de las publicaciones de la Universidad de Boyacá.

Comité Editorial de Ediciones Universidad de Boyacá: está conformado por el Representante Legal de la Institución o su delegado; el Vicerrector de Investigación Ciencia y Tecnología, el Director del Centro de Investigación para el Desarrollo - CIPADE y el Director de la División de Publicaciones.

Funciones del Comité Editorial:

- Estudiar y proponer la Política Editorial y direccionar las estrategias para su cumplimiento. 
- Evaluar y estudiar en conjunto la publicación de los proyectos editoriales de la Universidad.

- Proponer los criterios de evaluación de las publicaciones.

- Aprobar o rechazar la publicación de los textos sometidos a su conocimiento.

- Velar por la calidad de los proyectos editoriales y el buen manejo de la imagen del sello editorial.

Editor: encargado de la revisión y gestión de los proyectos editoriales.

Funciones del Editor:

- Proponer estrategias para la optimización del proceso editorial.

- Verificar el cumplimiento de los requerimientos de la Política Editorial de Ediciones Universidad de Boyacá.

- Someter los textos a pares externos (expertos) e interactuar con el autor(es) y pares, para adelantar procesos de evaluación.

- Revisar la originalidad de contenido de los textos, propiciando la citación del autor(es), ya sea en medios digitales o físicos.

- Efectuar acompañamiento a los procesos editoriales e indexación de revistas científicas.

- Gestionar y promover la actualización de la plataforma Open Journal Systems - OJS, de la Universidad de Boyacá. 
Corrector de texto y estilo: revisa y edita la escritura del texto: ortografía, gramática, sintaxis, estilo y formato.

Diseñador y diagramador de los textos: realiza la maquetación, carátula e ilustración de los proyectos editoriales.

\section{VISIÓN Y MISIÓN DE LA DIVISIÓN DE PUBLICACIONES}

La visión y la misión de las unidades académicas y administrativas se establecieron según la Resolución Rectoral Número 077 del 16 de junio de 2015; igualmente, en la Resolución 249 de 2018 se establecieron para la División de Publicaciones de la Universidad de Boyacá, así:

\subsection{Visión}

Ser líder en procesos editoriales en el ámbito universitario.

\subsection{Misión}

Visibilizar y difundir los productos derivados de las actividades investigativas, académicas, de proyección social y de extensión, bajo criterios de calidad científica y editorial.

\section{OBJETIVOS Y FUNCIONES DE LA DIVISIÓN DE PUBLICACIONES}

\subsection{Objetivo}

Producir y divulgar material editorial, resultado del quehacer académico, investigativo, de proyección social y de extensión, bajo parámetros de calidad científica y gráfica, siguiendo los estándares de editoriales. 


\subsection{Funciones según Acuerdo 060 del 2012, del Honorable Consejo de Fundadores Artículo Décimo Cuarto}

- Gestionar la publicación de productos académicos y de investigación.

- Evaluar las publicaciones bajo los criterios de calidad científica, académica y editorial.

- Proponer los procesos de divulgación de las publicaciones generadas en la Institución.

- Identificar pares evaluadores idóneos externos para la revisión de los productos a ser publicados por la Universidad.

- Coordinar los procesos editoriales de las revistas Institucionales.

- Propiciar el intercambio o donación de material publicado por la Universidad de Boyacá con otras universidades, centros de investigación o instituciones nacionales o internacionales.

- Coordinar el trabajo del equipo editorial, verificando la calidad de los productos generados.

- Proponer alternativas de publicación en medios impresos y electrónicos que promuevan la visibilidad de los productos.

- Generar material editorial que evidencie la producción académica e investigativa, bajo parámetros de calidad, siguiendo los estándares de editoriales universitarias. 


\section{GESTIÓN EDITORIALY PUBLICACIÓN}

\subsection{Clasificación de proyectos editoriales}

Ediciones Universidad de Boyacá promueve e impulsa la publicación de proyectos editoriales, individuales o colectivos, en los diferentes campos del saber, permitiendo la circulación, visibilidad y difusión del conocimiento, producto de procesos científicos.

La Política Editorial establece diez modalidades de publicación entre las cuales se encuentran:

Libros resultado de investigación: publicaciones inéditas, producto de procesos de investigación, las cuales presentan y describen aspectos introductorios, relacionados con el abordaje teórico, específicos, que enmarcan lo metodológico, resultados y conclusiones. Estas publicaciones deben ser evaluadas y avaladas por dos pares internos y dos pares externos, reconocidos por su aporte al conocimiento.

Libros compendio de capítulos de investigación: publicaciones originales e inéditas donde se compilan resultados de investigación en capítulos de autoría individual o colectiva que integran un libro. Estos textos requieren la evaluación de dos pares internos y dos pares externos, reconocidos por su aporte al conocimiento.

Libros producto de actividades de proyección social y de extensión: publicaciones que dan cuenta de los resultados de los proyectos y actividades de proyección social y extensión en las que se interactúa con agentes sociales. Estas requieren la evaluación de dos pares internos.

Libros de texto de pregrado y postgrado: publicaciones con una finalidad pedagógica y carácter didáctico. Pueden incluir contenidos de curso, manuales, guías, talleres, laboratorios, entre otros; se emplean como soporte y complemento a las diferentes actividades académicas de los cursos que integran los programas académicos. Estos textos requieren la evaluación de un par interno y un par externo. 
Libros de conocimiento especializado: publicaciones como compilaciones de memorias, working paper producto de diferentes eventos académicos y cientíícos; estos textos son sometidos a la evaluación de un par interno.

Libros de ensayo: publicaciones inéditas escritas de forma narrativa y literaria, que comprenden la producción intelectual de miembros de la comunidad científica, como resultado de su experiencia y quehacer académico. Estos textos requieren la evaluación de dos pares internos; en caso de que sean resultado de investigación se someterán a dos pares externos.

Libros institucionales: publicaciones inéditas que incluyen procesos académicos y/o administrativos.

Colecciones: publicaciones inéditas de libros seriados que pueden ser resultado de investigación y/o académicos, dependiendo la tipología del libro se someten a uno o dos pares internos y uno o dos pares externos.

Catálogos: publicaciones seriadas producto de exposiciones, eventos, fotografías, entre otros.

Revistas: publicaciones periódicas que contienen información científica o de divulgación, de carácter multidisciplinar o específico en un área del conocimiento. Las revistas disponen de un comité editorial y son sometidas a un proceso de arbitraje. Cada revista de Ediciones Universidad de Boyacá cuenta con un editor quien es el encargado de llevar a cabo el proceso editorial, asimismo, tiene la facultad para construir la política y las normas editoriales, atendiendo a las directrices del código de conducta de publicaciones científicas Committe on Publication Ethics [COPE].

Revistas científicas: compilación de publicaciones inéditas, editadas periódicamente (anual, semestral, cuatrimestral, trimestral, publicación continua...) que dan cuenta de los avances en ciencia, tecnología e innovación, por medio de trabajos investigativos originales, en las diferentes áreas del conocimiento. Estas revistas publican artículos en las modalidades: investigación científica y tecnológica, reflexión, revisión, artículo corto y editorial. Algunas cuentan con 
secciones para reporte de caso, revisión de tema, cartas al editor, y traducción. Estas publicaciones deben cumplir con las características y requisitos expuestos por Publindex.

Revistas académicas: compilación de publicaciones inéditas, editadas periódicamente (anual, semestral, cuatrimestral, trimestral, publicación continua...), que posibilitan el acceso al conocimiento científico y técnico que producen docentes, estudiantes y otros grupos de la comunidad universitaria, propiciando la divulgación y circulación de saberes en la comunidad académica y científica.

\subsection{Criterios de publicación}

Los proyectos editoriales presentados por la comunidad educativa a la Vicerrectoría de Investigación Ciencia y Tecnología y a los Comités de Investigación, deben atender los criterios estipulados en la Política Editorial; estas instancias realizan un proceso riguroso de evaluación que asegura la calidad científica, el compromiso ético y las adecuadas prácticas editoriales, conforme a las directrices del Código de Conducta sugerido por el COPE. Para lo anterior se cuenta con una serie de criterios básicos que guían estas prácticas:

\section{Académicos:}

Aportes al conocimiento y su influencia en la innovación, brindando estrategias o herramientas que propicien el fortalecimiento de la comunidad académica y científica, para contribuir al análisis y superación de las problemáticas del contexto.

Pertinencia académico-investigativa e impacto en los diferentes ámbitos académicos, social, económico y político, donde se comprenda el contenido y su relación con los aportes, la actualidad del tema, la originalidad y la rigurosidad con la que se abordan los argumentos y resultados.

Diseño del estudio y aprobación ética; toda obra ya sea académica o producto resultado de investigación debe contar con una justificación, una exhaustiva explicación de las ideas, un diseño metodológico adecuado y la aprobación del Comité de Ética y Bioética. 
Análisis de datos. Los proyectos editoriales, producto de investigación, deben incluir el compromiso de demostrar las fuentes y los métodos utilizados en la adquisición y el análisis de los datos, los cuales requieren una explicación detallada dentro del diseño para llegar a los resultados del estudio.

\section{Normativos:}

Autoría: el(los) autor(es) asume(n) la responsabilidad del contenido producido dentro del proyecto editorial. Con el fin de evitar conflictos entre autores por el crédito académico, se debe establecer, desde el inicio del proceso, el carácter de la obra, la cual puede ser individual, colectiva o por colaboración.

Conflicto de intereses: se refiere a los posibles conflictos entre autores, editores o árbitros lectores, que tienen relación explícita con la publicación ya sea comercial, personal, académica o financiera y pueden afectar la evaluación o la publicación. Este tipo de conflictos se darán a conocer en el Comité Editorial, donde se tomarán las decisiones pertinentes al caso.

Publicación redundante: cuando en una publicación se repiten las ideas tratadas, en relación con el mismo documento o a otros del mismo autor(es); pueden ser válidas cuando se requiere una confirmación ulterior. El autor(es) debe dar a conocer si esta publicación u otros documentos similares, están por ser publicados en otro idioma o medio.

Plagio: copia realizada de las ideas de otros, sin reconocimiento. Este varía desde la ausencia de la referencia al citar las ideas, textuales o parafraseadas, publicadas, hasta las ideas sin publicar. Todas las fuentes deben citarse debidamente según las normas.

Editoriales: se publicarán obras inéditas, que fortalezcan la visibilidad de Ediciones Universidad de Boyacá. En caso de que se presente una obra que es traducida de su idioma nativo a otro, esta debe contar con los permisos de publicación de cada autor y/o la entidad donde se encuentra publicada, según sea el caso. 


\subsection{Directrices de publicación}

Las publicaciones realizadas por la Editorial deberán tener el aval institucional dado por la Vicerrectoría de Investigación Ciencia y Tecnología de la Universidad de Boyacá, quien garantiza la calidad y el empleo de la imagen institucional; asimismo, deben contar con el ISBN o ISSN, ficha catalográfica, página legal, presentación realizada por la Rectoría, tabla de contenido, bibliografía y el código de barras. Además, los libros impresos contemplan:

- Carátula: debe contener la imagen gráfica representativa de la Universidad de Boyacá, acompañada por la identificación de la facultad a la que se adscribe el texto, el título de la obra y autor(es). Cuando el Proyecto Editorial sea producto de investigación se incluirá la denominación del Centro de Investigaciones para el Desarrollo - CIPADE.

- Solapas: incluyen el texto de presentación del autor(es) y, de ser requerida, la fotografía de estos, además, debe incluir un resumen de su currículum.

- Página de cortesía: página en blanco o con una imagen representativa del texto, contiene la ficha catalográfica en la cara posterior.

- Portadilla: contiene título de la obra, autor(es), editor(es) o compilador(es), la imagen gráfica de la Universidad de Boyacá (logo), acompañada por la identificación de la facultad a la que se adscribe el texto y denominación del Centro de Investigaciones para el Desarrollo - CIPADE, (esto cuando el proyecto editorial sea producto de investigación).

- Página legal: presenta el cuerpo directivo de la Universidad de Boyacá (Presidente, Rector, Vicerrectores y Decanos de la facultad a la que pertenece la publicación), seguido por el símbolo $\odot$ (Copyright) y el autor(es); continúa con el Director del Centro de Investigaciones para el Desarrollo - CIPADE (esto cuando el Proyecto Editorial sea producto de investigación), seguido por el Director de la División de Publicaciones, equipo editorial (gestión editorial, corrección de texto y estilo, ilustraciones, diseño y diagramación), posteriormente, símbolo $\odot$ (Copyright) con Ediciones Universidad de Boyacá, dirección, teléfono, contacto, ciudad, ISBN, derechos de propiedad de la Universidad de Boyacá, 
año de publicación, leyenda: “Esta edición y sus características gráficas son propiedad de la Universidad de Boyacá", (logo), ( (Copyright) y año de publicación. Finaliza con "Queda prohibida la reproducción parcial o total de este libro, por medio de cualquier proceso repográfico o fónico, especialmente fotocopia, microfilme, offset o mimeógrafo (Ley 23 de 1982)".

- Páginas preliminares: incluyen agradecimientos, tabla de contenido y presentación del texto.

- Colofón: se debe imprimir en la última página impar, donde se incluirá: fecha de terminación de la impresión y nombre del taller de impresión.

- Cubierta posterior: contiene el sello editorial y código de barras.

- Lomo: título de la obra, nombre del autor(es) y logo de la Universidad de Boyacá.

\subsection{Mecanismos de visibilidad y accesibilidad}

Los proyectos editoriales de Ediciones Universidad de Boyacá se encuentran disponibles en medio físico, en espacios como la Politeca y los centros de documentación de las facultades. De igual forma, se realiza canje interbibliotecario con universidades en convenio o donación a diferentes instituciones. Sumado a esto, los libros son comercializados en la Universidad de Boyacá y a través de distribuidores a nivel nacional, en medio físico y venta en línea, quienes participan con las publicaciones en ferias nacionales e internacionales. Ediciones Universidad de Boyacá, cuenta con un sitio web en el cual se visibiliza el catálogo de libros publicados.

\section{COMUNICACIONES}

La comunicación entre la Vicerrectoría de Investigación Ciencia y Tecnología y los diferentes entes involucrados en el proceso de evaluación y publicación de los proyectos editoriales, se llevará a cabo por medio electrónico, vicerrectoria-ict@uniboyaca.edu.co con copia al correo electrónico publicaciones@uniboyaca.edu.co. 


\section{REFERENCIAS}

Acuerdo 039 de 1984 [Honorable Consejo Directivo de la Universidad de Boyacá]. Por el cual se adopta el Estatuto Orgánico y se determinan las funciones de sus dependencias. Enero 28 de 1984.

Acuerdo 335 de 2002 [Honorable Consejo Directivo de la Universidad de Boyacá]. Por el cual se modifica el Acuerdo No. 01 de 1993 y se reforma la Estructura Orgánica de la FUNDACIÓN UNIVERSITARIA DE BOYACÁ. Marzo 01 de 2002.

Acuerdo 020 de 2003 [Honorable Consejo de Fundadores de la Universidad de Boyacá]. Por el cual se reforman los Estatutos Generales de la Universidad de Boyacá. Marzo 14 de 2003.

Acuerdo 060 de 2012 [Honorable Consejo de Fundadores de la Universidad de Boyacá]. Por el cual se crea la División de Publicaciones. Marzo 12 de 2012.

Acuerdo 093 de 2018 [Honorable Consejo de Fundadores de la Universidad de Boyacá]. Plan de Desarrollo Institucional. Diciembre 10 de 2018.

Acuerdo 1178 de 2018 [Honorable Consejo Directivo de la Universidad de Boyacá]. Política Editorial de la Universidad de Boyacá. Noviembre 15 de 2018.

Caballero, J. (2004). Derecho de Autor para Autores. México D.F.: Libros sobre Libros - Fondo de Cultura Económica - CERLALC. ISBN 968-16-7450-2 (fce).

Comisión Nacional de los Derechos Humanos. (2012). Pacto Internacional de Derechos Económicos, Sociales y Culturales de las Naciones Unidas. México D.F, México.

Committe On Publication Ethics. (2008). Code of Conduct. Recuperado de: https://publicationethics.org/resources/code-conduct 
Congreso de la República. (1982). Ley 23 sobre derechos de autor. Artículo 30. Colombia.

Constitución Política de Colombia [Const]. Art. 61. Julio 7 de 1991 (Colombia).

Convenio de Berna. (1886). "Para la protección de las obras literarias y artísticas". Septiembre 9 de 1886. Recuperado de: http://www.wipo.int/treaties/es/text.jsp?file_id=283700

Decisión 351 de 1993. Régimen Común sobre Derecho de Autory Derechos Conexos. Diciembre 17 de 1993. Recuperado de: http://www.wipo.int/edocs/lexdocs/laws/es/can/can010es.pdf

Decreto 460 de 1995. Reglamentación del registro nacional del Derecho de Autor y regulación del depósito legal. Marzo 16 de 1995. Recuperado de http://www.unesco.org/culture/ natlaws/media/pdf/colombia/colombia_decreto_460_16_03_1995_spa_orof.pdf

Decreto 0162 de 1996. Reglamenta la Decisión Andina No. 351 de 1993 y la Ley 44 de 1993, en relación con las Sociedades de Gestión Colectiva de Derecho de Autor o de Derechos Conexos. Enero 22 de 1996. Recuperado de: http://www.wipo.int/edocs/lexdocs/laws/es/ co/co030es.pdf

Decreto 1162 de 2010. Se organiza el Sistema Administrativo Nacional de Propiedad Intelectual y se crea la Comisión Intersectorial de Propiedad intelectual. Abril 13 de 2010. Recuperado de: https://www.ica.gov.co/getattachment/3b286732-e97b-4d98-8ce1-e8da38e76 c5f/2010D1162.aspx

Decreto 460 de 1995. Reglamentación del Registro Nacional del Derecho de Autor y Regulación del Depósito Legal. Marzo 16 de 1995. Recuperado de: http://bibliotecanacional.gov.co/ es-co/servicios/profesionales-del-libro/Documents/DECRETO-460-DE-1995.pdf

Kleinert, S., \& Wager, E. (July 2010). Responsible research publication: international standards for editors. The 2nd World Conference on Research Integrity, Singapore, 22-24. Recuperado de https://publicationethics.org/files/International\%20standard_editors_for\%20 website_11_Nov_2011.pdf 
Ley Estatutaria 1266 de 2008. Por la cual se dictan disposiciones generales del Habeas Data y se regula el manejo de la información contenida en bases de datos personales, en especial la financiera, crediticia, comercial, de servicios y la proveniente de terceros países y se dictan otras disposiciones. Diciembre 31 de 2008. Recuperado de: http://wp.presidencia. gov.co/sitios/normativa/leyes/Documents/Juridica/Ley\%201266\%20de\%2031\%20 de\%20diciembre\%202008.pdf

Ley 1712 de 2014. Ley de Transparencia y del Derecho de Acceso a la Información Pública Nacional y se dictan otras disposiciones. Marzo 6 de 2014. Recuperado de: http://www. centrodememoriahistorica.gov.co/descargas/transparencia/Ley1712-transparencia-acceso-informacion.pdf

Ley 1834 de 2017. Se fomenta la economía creativa. Mayo 23 de 2017. Recuperado de: http:// es.presidencia.gov.co/normativa/normativa/LEY\%201834\%20DEL\%2023\%20DE\%20 MAYO\%20DE\%202017.pdf

Ley 1915 de 2018. Se modifica la ley 23 de 1982 y se establecen otras disposiciones en materia de Derecho de Autor y Derechos Conexos. Julio 12 de 2018. Recuperado de: http:// es.presidencia.gov.co/normativa/normativa/LEY\%201915\%20DEL\%2012\%20DE\%20 JULIO\%20DE\%202018.pdf

Ley Número 23 de 1982. Sobre derechos de autor. Enero 28 de 1982. Recuperado de: http:// derechodeautor.gov.co/documents/10181/182597/23.pdf/a97b8750-8451-4529-ab87bb82160dd226

Ley 44 de 1993. Por la cual se modifica y se adiciona la Ley 23 de 1982 y se modifica la Ley 29 de 1944. Febrero 5 de 1993. Recuperado de: http://www.colmayor.edu.co/uploaded_ files/images/archivos/normograma/leyes/Ley44de1993(semodificayadicionalaley23de1982ysemodificalaley29de1944(derechosdeautor).pdf 
Ley 565 de 2000. Tratado de la OMPI - Organización Mundial de la Propiedad Intelectual sobre Derechos de Autor (WCT). Febrero 2 de 2000. Recuperado de: http://www.wipo. int/edocs/lexdocs/laws/es/co/co072es.pdf

Ley 599 de 2000. Por la cual se expide el Código Penal. Julio 24 2000. Recuperado de: https:// www.unodc.org/res/cld/legislation/can/codigo-penal_html/Codigo_Penal.pdf

Ley 1379 de 2010. Por la cual se organiza la red nacional de bibliotecas públicas y se dictan otras disposiciones. Enero 15 de 2010. http://www.mincultura.gov.co/ministerio/oficinas-ygrupos/oficina\%20asesora\%20de\%20planeacion/Documents/Ley\%201379-2010\%20 Art\%2041.pdf

Olarte, J.M., \& Rojas, M.A. (2010). La protección del derecho de autor y los derechos conexos en el ámbito penal. Dirección Nacional de Derecho de Autor. Ministerio del Interior y de Justicia. Recuperado de: http://derechodeautor.gov.co/documents/10181/11769/ $\mathrm{La}+$ proteccin+del+derecho+de+autor+y+los+derechos+conexos+en+el+ambito+penal+sep+15+de+2010.pdf/75686fc1-c9be-4dc3-b1d5-efcd5f4be949

Rangel, D. (1992). Derecho de propiedad industrial e intelectual. Segunda Edición México: Universidad Nacional Autónoma de México. Citando a Satanowsky Derecho intelectual. T.1, Argentina, p. 153.

Resolución Rectoral 077 de 2015 [Rectoría de la Universidad de Boyacá]. Por la cual se establecieron la visión y la misión de las unidades académicas y administrativas y de la División de Publicaciones de la Universidad de Boyacá. Junio 16 de 2015.

Resolución Rectoral 249 de 2018 [Rectoría de la Universidad de Boyacá]. Por la cual se reglamenta la Misión y Visión de las unidades Académicas y Administrativas de la Universidad de Boyacá. Octubre 12 de 2018. 
Rey, C. (2005). La propiedad intelectual como bien inmaterial. Colombia, Bogotá: Ed. Leyer.

Rojina, R. (1985). Derecho civil mexicano Sexta Edición. México D.F., México: Porrúa.

Serrano, F. (1998). El Derecho Moral. Presentado en el Seminario Regional de la OMPI sobre Derechos de Autory Derechos Conexos para profesores universitarios del Istmo Centroamericano. Antigua, Guatemala. 